\title{
A STUDY ON ENHANCING THE FLAME RETARDANCY OF POLYPROPYLENE YARN WITH BORON COMPOUNDS
}

DOI: $10.35530 /$ TT.2021.22

\author{
E. Eskiyapar ${ }^{1 *}$, H.K. Kaynak ${ }^{1}$, H.İ. Çelik ${ }^{1}$, E. Sarıoğlu ${ }^{2}$ \\ ${ }^{1}$ Textile Engineering Department, Gaziantep University, Gaziantep, Turkey \\ (E-mail: edaeskiyapar@gmail.com, tuluce@gantep.edu.tr, hcelik@gantep.edu.tr) \\ ${ }^{2}$ Textile and Fashion Design Department, Gaziantep University, Gaziantep, Turkey \\ (E-mail: sarioglu@gantep.edu.tr)
}

\begin{abstract}
Functional properties such as; water resistance, flame retardancy, antibacterial efficiency etc. are required from textile products. One of the most commonly demanded products among functional textile products is the flame-retardant textiles. In this study, it is aimed to produce polypropylene filament yarn with permanent flame retardancy functionality by adding boron compound, which is Anhydrous disodium tetraborate powder (particle size < 38 micron), to the fiber structure during melt spinning process. In this study two different yarn samples are produced with anhydrous disodium tetraborate content by mass ratios of $2 \%$ and 5\%. A control polypropylene filament yarn sample is also produced with no additive. By this way, three samples are produced by a conventional BCF polypropylene melt spinning machine with the same production parameters. Then, three knitted fabric samples were produced flat knitting machine. Limiting Oxygen Index (LOI) and vertical flammability tests were applied to the samples. According to results an important level of increase for LOI value is obtained with the sample which has 2\% boron compound additive. Nevertheless, there is not a consistent effect of increasing boron content in yarn structure for LOI value. The reason of this situation may be resulted due to the uneven distribution of the boron compound in the yarn structure because of the particle size.
\end{abstract}

Keywords: Anhydrous disodium tetraborate, Boron compound, filament yar, flame retardancy, polypropylene

\section{INTRODUCTION}

Today, functional properties such as; water resistance, flame retardancy, antibacterial efficiency etc. are required from textile products. Flame retardant applications are mainly applied to combustible textile materials used in carpets, curtains and children's wear for avoiding easily flammable fabrics. In principle, the best flame retardant process for textile materials have to char the fiber, prevent afterglow and release no toxic gas or smoke. The new regulations regarding environment, health and fire require halogenated flame retardant chemicals to be phased out. Today, researchers concentrate on creating halogen free flame retardants for different kinds of textile materials. The modern flame retardant chemistry uses silicone, phosphorus and nitrogen compounds. Researches focus on green chemistry such as enzymes and intumescent flame retardants like expandable graphite as well. Inorganic compounds and interactive combinations of conventional flame retardants are likewise in demand [1]. On the other hand, providing permanence of the functionality is as important as obtaining flame retardancy. Polypropylene is a widely 
used synthetic polymer due to its high strength and low-price advantages. On the other hand, it has a disadvantage that the material burns very quickly and does not leave ash residue, but it is an advantage that it burns smokeless [2]. Flame retardancy for textile products can be achieved by different ways; as using commercially available flame retardant fibers, finishing of textile products by flame retardant chemicals or adding flame retardant additives to the structure during fiber production [3].

In the literature there are many studies which deal with the flame retardancy effect of boron compounds. In a previous study, various boron compounds were used to achieve flammability. The synergistic effect of four different boron containing substances, zinc borate, borophosphate, boron silicon containing preceramic oligomer and lanthanum borate were used to increase the flame retardancy of a polypropylene intumescent system composed of ammonium polyphosphate and pentaerythritol. LOI test results showed that boron compounds reach their highest synergistic effect at $1 \%$ wt loading. Borophosphate containing composite showed the highest LOI value of 30, lowest maximum heat release rate and lowest total heat release rate value. Even though the char yield increases as the amount of boron compounds increases, the flame retarding effect decreases. Results of cone calorimeter test and thermogravimetric analysis showed that the boron compounds are likely to achieve their synergistic effect by reinforcing the integrity of char which improves its barrier effect rather than increasing the char yield [4]. In another research, effect of commercial flame retardant (CFR) on upholstery leathers treated with borax, boric acid and zinc borate was investigated. Chemical solutions were applied to the leathers by padding finishing technique, and after the flame retardant application the leathers were finished with traditional finishing methods. According to LOI results, CFR CFR+borax+boric acid and CFR+zinc borate+boric acid treated groups of leather had 28.5\%, 29.2\% and 29.9\% oxygen concentration, while control sample had $27.0 \%$. It is concluded that, flame retardant property of leathers was increased by the effect of boron derivatives [5]. In a study which deals with the flame retardancy of zinc borate, organic phosphinate (diethyl phosphinic acid) (DPA) and zinc borate/organic phosphinate combination doped polybutylene terephthalate (PBT) was investigated. LOI values of $\mathrm{ZnB} / \mathrm{PBT}$ samples were found very low even with higher filling content. At higher loading of $\mathrm{ZnB}$, the dripping of the sample strongly decreased and also char residue increased. It was concluded that organic phosphinate acid-based additives DPA was particularly effective with PBT. It was also seen that the combination of DPA and $\mathrm{ZnB}$ can be used to increase the char residue and decrease the melt dripping of PBT [6]. In another study, neutralized intumescent fire retardant (NIFR) was synthesized in "one step and one pot" using a protocol. Flame retardant properties of the intumescent polypropylene showed the efficiency of the new synthesized intumescent compound. It was also demonstrated that, under hydrolytic conditions, zinc borate allowed reducing the migration and keeping good flame retardant properties [7]. Ayar et al. aimed to produce, economically favourable, easy processed, strong coverageable, flame retardant, high temperature resistant, low temperature expansion and high corrosion resistance dye by means of anhydrous zinc borate pigment. According to test results, it is approved that thermal and fire resistance of metallic, wooden and woven textile materials were improved by means of anhydrous zinc borate based pigment dye. This dye can be used to increase the materials resistance against extreme temperature, corrosion and to provide dimensional stability in industrial applications [8].

In another study, two eco-friendly boron chemicals, boric acid, and borax decahydrate, were used as flame-retardant. The flame-retarding functions for polypropylene bulked continuous filament polypropylene (BCF PP) yarn were investigated through the applications of boron chemicals. Boric acid and borax decahydrate are added to BCF PP 
yarns during the spin finish process. LOI values of samples were examined and the results of the study showed that application of boron compounds improves flame retardancy. Borax decahydrate shows better flame-retarding effect than boric acid [9]. Another study is about boron oxide and boric acid application to impart flame retardant property for comonomer containing polyacrylonitrile fabrics. In the study, boron compounds were applied to fabrics by using various combinations of the atmospheric plasma modification and sol-gel methods. After these treatments, ignition times of the atmospheric plasma and sol-gel treated fabrics were compared. Test results showed that, ignition times of all the samples treated with boron oxide and boric acid were increased, but the highest increase was obtained by the plasma+sol-gel method. SEM (Scanning Electron Microscopy) images and FT-IR (Fouriertransform infrared spectroscopy) spectrums of the treated samples demonstrated the presence of boron in all samples treated under various conditions. When TGA (Thermogravimetric analysis) thermograms were examined, it was determined that the decomposition temperature of PAN fabrics, treated with boron compounds increased. It is concluded that the flame retardancy of PAN (Polyacrylonitrile) fabrics was improved by environmentally friendly boron compound application [10]. In a study, flame retardancy effect of boron on two cotton fabrics was investigated. Different concentrations of boric acid nanoparticles were examined to optimize the flame-retardant functions. Results showed that; the flame spreading times of the coated fabrics and burning time were increased by increasing the concentration of boric acid nanoparticle content. In addition, tensile strength of the treated fabric decreased [11]. In a study which deals with the the effects of zinc borate (ZB) and micro capsulated red phosphorus (MRP) with modified magnesium hydroxide $(\mathrm{MH})$ on the flame-retardancy property of polypropylene (PP), it is seen that the MRP powders had a little effect on the mechanical properties of the PP composites. Test results showed that addition of $\mathrm{ZB}$ and MRP weakened the heterogeneous nucleation effect of $\mathrm{MH}$ on PP. The addition of $\mathrm{ZB}$ and MRP had a great effect on the flammability of the $\mathrm{PP} / \mathrm{MH} / \mathrm{EG}$ composites. The thermal stability of $\mathrm{PP} / \mathrm{MH} / \mathrm{ZB}$ and $\mathrm{PP} / \mathrm{MH} / \mathrm{ZB} / \mathrm{MRP}$ composites was better than that of $\mathrm{PP} / \mathrm{MH}$ composite [12]. Güldaş et al. studied the rheological properties of zinc borate reinforced polypropylene. In the study reinforced polypropylene granules were produced and the zinc borate was added to powder polypropylene material at different ratios. To prevent oxidation, maleic anhidrit used as an antioxidant, it was added to PP during the production of zinc borate reinforced polypropylene granule. It was determined that viscosity value increased depending on zinc borate rate but viscosity decreased depending on increasing temperature and pressure. It was determined that MFI (melt flow index) values had been increased depending on increasing temperature and pressure whereas MFI values have been decreased according to increasing zinc borate ratio. Additionally, shear rate decreased depending on increasing proportion of additive but shear rate increased with the increasing of temperature and pressure [13].

In the present study, it is aimed to produce polypropylene filament yarn with permanent flame retardancy functionality by adding boron compounds to the fiber structure during melt spinning process. It is known that boron compounds are flame retardant, environmentally friendly when used, do not cause toxic gas emissions, have low volatility, and suppress combustion by covering the burning material in such a way that prevent the contact of burning material with oxygen [14].

\section{MATERIALS AND METHOD}

In this study, Anhydrous disodium tetraborate (Etibor 68) which is produced by ETİ Mining Operations General Directorate (Turkey) is used. The master batch is 
produced via twin screw extruder by mixing Anhydrous disodium tetraborate powder (particle size $<38$ micron) by polypropylene polymers. For production of masterbatch, polypropylene and anhydrous disodium tetraborate are mixed by a mass basis ratio of 50/50. Then, three different polypropylene filament yarn samples are produced by a conventional BCF polypropylene melt spinning machine with 3000 dtex/144f yarn linear density. Two samples are produced with $2 \%$ and $5 \%$ (weight basis) anhydrous disodium tetraborate additive. The control sample is produced without additive. The production parameters of the sample yarns are given in table 1.

Table 1. The production parameters of yarn

\begin{tabular}{|c|c|}
\hline Parameter & Value \\
\hline Temperature of extruder & $220^{\circ} \mathrm{C}-250^{\circ} \mathrm{C}$ \\
\hline Cooling air velocity & $0.7 \mathrm{~m} / \mathrm{s}$ \\
\hline Temperature of air chamber & $20^{\circ} \mathrm{C}$ \\
\hline Lubrication rate (spin finish) & $0.7 \%$ \\
\hline Tailstock & $28 \mathrm{pcs} / \mathrm{m}-30 \mathrm{pcs} / \mathrm{m}$ \\
\hline Spot pressure & $4.5 \mathrm{bar}$ \\
\hline Output Speed & $2800 \mathrm{~m} / \mathrm{min}$ \\
\hline
\end{tabular}

The produced yarn samples are used to produce knitted fabrics by flat knitting machine. Then, Limiting Oxygen Index (LOI) of yarns is measured according to ASTM D2863 standard. Flammability behaviors of knitted fabrics are also measured by vertical flammability test according to ASTMD 6413 - 08 method.

\section{RESULTS}

In this study, surface views of produced yarns are examined by SEM images and given in figure 1.

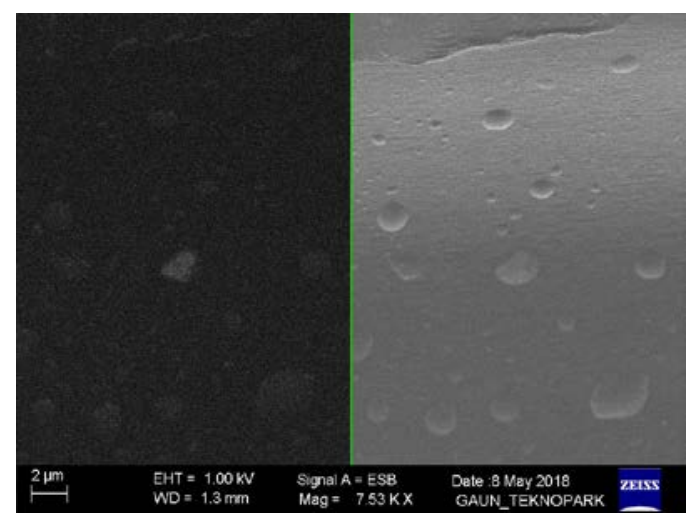

Figure 1. SEM images, with 2\% (left side) and 5\% (right side) anhydrous disodium tetraborate additives

It can be seen from SEM results that the boron compound is not evenly distributed on the surface of yarn. It is thought that, the particle size of boron compound (38 micron) is not suitable for yarn production; as a result the particle size of compound must be lowered.

LOI is the measure of the minimum percentage of oxygen in an oxygen/nitrogen mixture that is required to support the combustion of material. LOI values of samples are determined and are given in table 2 . 
Table 2. LOI (Limiting Oxygen Index) of yarns

\begin{tabular}{|c|c|}
\hline Samples & LOI (\%) \\
\hline Without boron additive & 19.0 \\
\hline \%2 anhydrous disodium tetraborate & 22.1 \\
\hline \%5 anhydrous disodium tetraborate & 20.6 \\
\hline
\end{tabular}

It can be seen from LOI values that the yarn without boron additive has a very low value which can be regarded as easily flammable. It is also seen that better results are obtained with the sample which has $2 \%$ boron compound additive in comparison to control sample (without boron additive). However, the same trend is not seen in 5\% boron additive yarn. Flammability behaviours of knitted fabrics were measured by vertical flammability test and the results are given in table 3.

Table 3. Vertical flammability test results

\begin{tabular}{|l|c|c|c|c|}
\hline \multicolumn{1}{|c|}{ Parameter } & \multicolumn{4}{c|}{ Value } \\
\hline Control sample & $\mathbf{1}$ & $\mathbf{2}$ & $\mathbf{3}$ & Mean \\
\hline Self-extinguishing time, second & 86 & 48 & 55 & 63 \\
\hline Combustion distance, cm & 20 & 10 & 13 & 14.3 \\
\hline $\mathbf{2 \%}$ anhydrous disodium tetraborate & $\mathbf{1}$ & $\mathbf{2}$ & $\mathbf{3}$ & Mean \\
\hline Self-extinguishing time, second & 40 & 75 & 12 & 42.3 \\
\hline Combustion distance, cm & 8 & 20 & 6 & 11.3 \\
\hline $\mathbf{5 \%}$ anhydrous disodium tetraborate & $\mathbf{1}$ & $\mathbf{2}$ & $\mathbf{3}$ & Mean \\
\hline Self-extinguishing time, second & 50 & 125 & 40 & 71.6 \\
\hline Combustion distance, cm & 11 & 20 & 12 & 14.3 \\
\hline
\end{tabular}

After vertical flammability tests the sample views are taken and the images are given in figure 2.

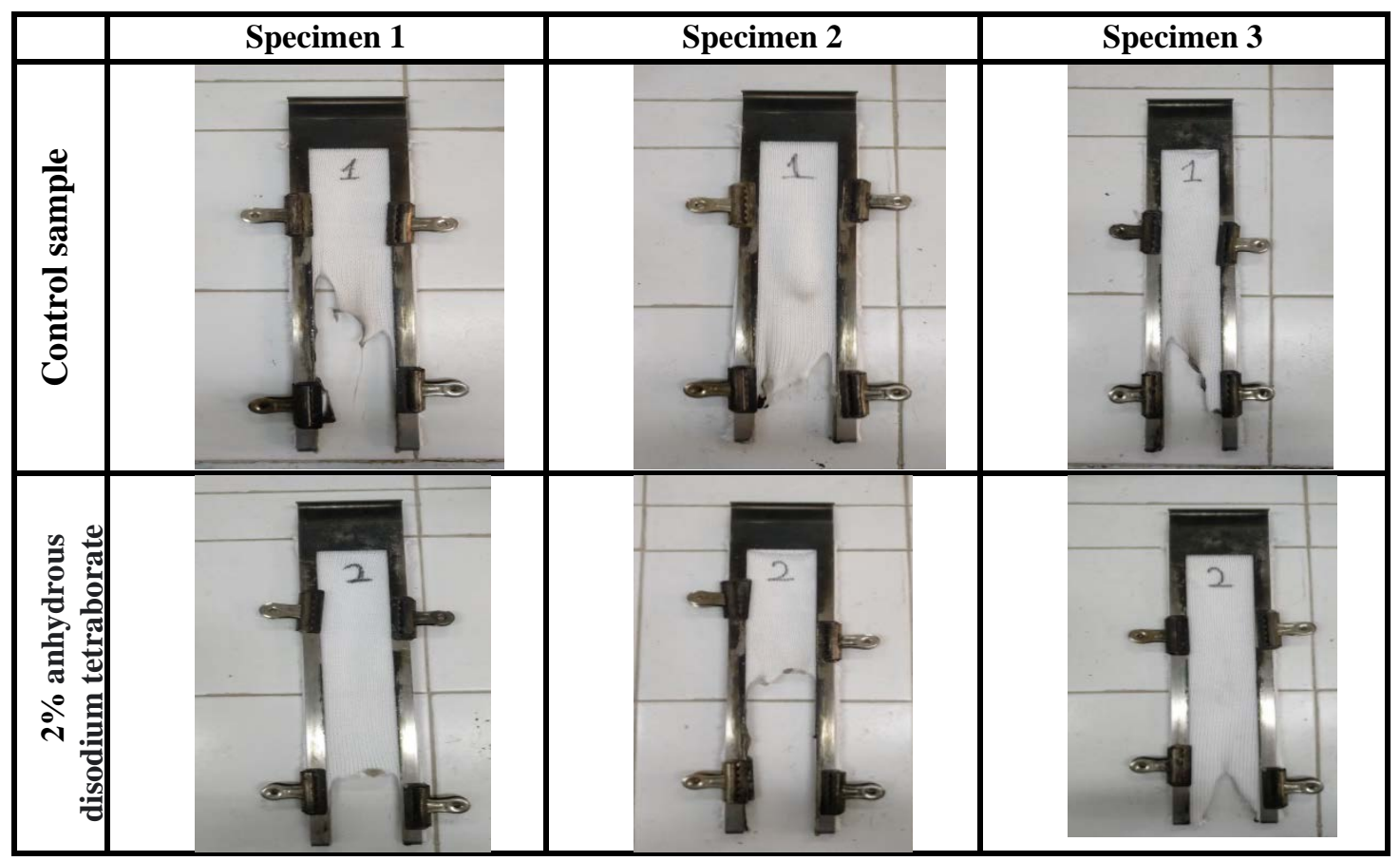




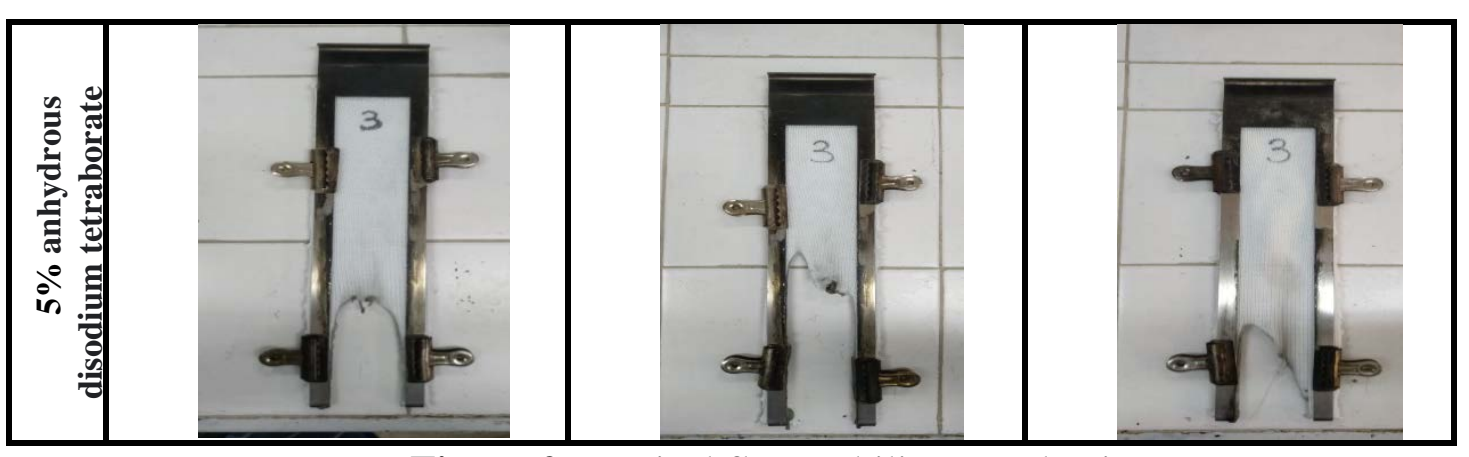

Figure 2. Vertical flammability sample views

It is seen from the sample images (figure 2) that the better results are obtained by the specimens, which have $2 \%$ boron compound additive in comparison to control sample. But the flame retardancy does not increase when the boron compound ratio increases. So, the flame retardancy of the boron compound is found to be inconsistent as a negative result.

\section{CONCLUSIONS}

The flame retardancy performance of the samples is investigated by LOI test and vertical flammability tests. An obvious level of increase for LOI value is obtained with the sample which has $2 \%$ boron compound additive. But there is not a consistent effect of increasing boron content in yarn structure for LOI value. This situation may be resulted due to the uneven distribution of the boron compound in the yarn structure. The probable reason is thought to be the inappropriate particle size of boron compound. Similar inconsistent results are also seen for vertical flammability test results. For this reason, for further study, the particle size of boron compounds will be reduced and also homogenization boron compound in the yarn structure will definitely be ensured. After the discussions with the synthetic yarn manufacturers, it was concluded that adding particles of approximately onetenth of the yarn diameter to the yarn structure would be suitable for synthetic yarn production. It is concluded that the particle size of 5 microns and below would be more sufficient for the boron compounds to be used.

\section{REFERENCES}

[1] Paul, R., Functional finishes for textiles: An overview, In: Performance and Protection, 2015, 114

[2] Zhang, S., Horrocks, A.R., A Review of Flame Retardant Polypropylene Fibres, In: Progress in Polymer Science, 2003, 28, 1517-1538

[3] Çerkez, İ., Butekom Akademi Tekstilde Özel Konular Cilt 2: Tekstil Ürünlerinde Güç Tutuşurluk Eğitim Kitapçı̆̆ı, BUTEKOM, 2015, ISBN: 978-605-65630-2-7

[4] Doğan, M., Y1lmaz, A., Bayraml1, E., Synergistic effect of boron containing substances on flame retardancy and thermal stability of intumescent polypropylene composites, In: Polymer Degradation and Stability, 2010, 95, 2584-2588

[5] Aç1kel, S.M., Development of Commercial Flame Retardant in Upholstery Leathers By Boron Derivatives, In: Tekstil ve Konfeksiyon, 2018, 28, 4, 319-323

[6] Üreyen, M.E., The Combined Effect Of Organic Phosphinate Based Flame Retardant And Zinc Borate on The Fire Behaviour of Poly(Butylene Terephthalate)", In: Anadolu University Journal of Science and Technology A- Applied Sciences and Engineering, 2016, 17, 5, 775-785

[7] Fontaine, G., Bourbigot S., Duquesne S., Neutralized flame retardant phosphorus agent: Facile synthesis, reaction to fire in PP and synergy with zinc borate, In: Polymer Degradation and Stability 2008, 93, 68-76 
[8] Ayar, B., Gürü, M., Çakanyıldırım, Ç., Solid Phase Synthesis of Anhydrous Zinc Borate from Zinc and Boron Oxide and Utilization as a Flame Retardant in Dye and Textile, In: Gazi University Journal of Science, 2014, 27, 3, 987-991

[9] Avcioğlu Kalebek, N., Functionalized Polypropylene Filaments for Flammability, In: INTECH, Textiles for Advanced Applications, 2017, 10, 275-291

[10] Bozacı, E., Borlu bileşiklerin çevre dostu yöntemlerle poliakrilnitril kumaşlara uygulanması, In: Journal of BORON, 2018, 3, 1, 17-23

[11] Akarslan, F., Investigation on Fire Retardancy Properties of Boric Acid Doped Textile Materials, In: Special issue of the International Conference on Computational and Experimental Science and Engineering (ICCESEN 2014), 2015, 128

[12] Chen, X., Yu, J., He, M., Guo, S., Luo, Z., Lu, S., Effects of zinc borate and microcapsulated red phosphorus on mechanical properties and flame retardancy of polypropylene/magnesium hydroxide composites, In: J. Polym. Res., 2009, 16, 357-362

[13] Güldaş, A., Çankaya, A., Güllü, A., Gürü, M., Determination of Rheological Properties of Zinc Borate Reinforced Polypropylene, In: Journal of the Faculty of Engineering and Architecture of Gazi University, 2014, 29, 2, 227-234

[14] Yılmaz Aydın, D., Gürü, M., Ayar, B., Çakanyıldırım, Ç., Bor bileşiklerinin alev geciktirici ve yüksek sicaklı̆̆a dayanıklı pigment olarak uygulanabilirliği, In: Journal of BORON, 2016, 1, 33-39 